\title{
An applicability assessment and sensitivity analysis of land use impact models: application of the LANCA model in site-specific conditions
}

\author{
D. Terranova ${ }^{1} \cdot$ E. Balugani $^{1} \cdot$ S. Righi ${ }^{1,2} \cdot$ D. Marazza $^{1,2}$ (D)
}

Received: 6 January 2021 / Accepted: 15 September 2021 / Published online: 11 October 2021

(c) The Author(s) 2021

\begin{abstract}
Purpose In this work, we study a land use impact model with the aim of obtaining spatially differentiated as opposed to default average characterisation factors. In particular, we study the application of LANCA $®$, a multi-indicator model with available country average characterisation factors expressing the alteration of the soil quality level of the current land use of one kind with respect to a reference situation.

Method To this purpose, we use the LANCA® method documentation at a higher spatial resolution and apply all the required elemental steps. From a user perspective, we score the transparency of the method down to the basic methodological references and single out the source of errors that the user may incur when: (i) collecting the input data, (ii) selecting the appropriate soil/land classes and (iii) applying the individual calculation steps. For a greater insight, we couple the source of errors with a sensitivity analysis.

Results In the comparison between a site-specific test area and the related country default values, we obtained relevant discrepancies regarding the erosion resistance and the physicochemical filtration of the soil. For example, we find that the erosion resistance potential is $-1.06 * 10^{-3} \mathrm{~kg} \mathrm{~m}^{2} \mathrm{a}^{-1}$ locally while the country default value is 13.1 . We explain differences through the sensitivity analysis and having analysed in depth the underpinned soil erosion equation and the critical steps for its calibration. Together with systematic errors, we find that the method generally implies 9 scarcely guided steps out of 42, and one-third of the basic methodologies are not fully explained or accessible. These factors make the results related to Biotic Production, Mechanical Filtration, Physicochemical Filtration and Groundwater Regeneration user dependent and — in this sense - difficult to replicate.
\end{abstract}

Conclusions From the analysis, we distil 7 main directions for improvement addressed to LANCA $®$ and soil models especially in sight of a broader application of a regionalised life cycle impact assessment.

Keywords Soil quality indicators $\cdot$ Land use $\cdot$ Impact assessment $\cdot$ Soil erosion $\cdot$ Regionalization $\cdot$ Spatial differentiation . RUSLE $\cdot$ Model applicability $\cdot$ Harmonised LCIA methods

\section{Introduction}

The complexity of soil functioning requires reliable models for the life cycle impact assessment. Many LCA studies have recently tried to account for human-induced land use

Communicated by Matthias Finkbeiner.

D. Marazza

diego.marazza@unibo.it

1 CIRSA, Centro Interdipartimentale di Ricerca Delle Scienze Ambientali, University of Bologna, Via S. Alberto 163, 48123 Ravenna, RA, Italy

2 DiFa, Department of Physics, University of Bologna, Viale B. Pichat 6/2, 40123 Bologna, BO, Italy impacts that negatively affect soil quality (Koellner et al. 2013a, b; Vázquez-Rowe et al. 2014; Vidal Legaz et al. 2017). However, with respect to other impact categories such as global warming, a general consensus about land use implication in life cycle studies has not yet been found (Garrigues et al. 2012; Hellweg and Mila i Canals 2014). In LCIA models, the environmental interventions are assigned qualitatively to a particular impact category, and impacts are quantified in terms of a common unit for that category, allowing aggregation into one figure of the indicator result. Different strategies to capture the soil complexity into one figure have resulted in different models of LUC impacts on soil quality; insofar, a widely accepted approach is still missing (Koellner et al. 2013a, b; Vidal Legaz et al. 2017; 
Sonderegger et al. 2020). These models mainly differ in terms of which soil quality indicators have been selected and the spatial resolution the models are suited for. Generally, multi-indicator models are more complete in scope, environmentally relevant and scientifically robust but, at the same time, they are difficult to apply: a large amount of input data categories is typically required; consequently, the model structure may be difficult to understand. On the other hand, single-indicator models are more accessible and less time-consuming while their degree of complexity may be too limited to study effectively the phenomenon. Other differing aspects of characterization models principally concern occupation and transformation as different types of soil quality impacts, inclusion of soil quality regeneration period, time frame considered. The model proposed by Milà i Canals and co-authors (Milà Canals et al. 2007), currently recommended by ILCD (EC-JRC 2011), for instance, uses the soil organic carbon (SOC) as single indicator at a globalscale resolution. On the other hand of the model spectrum, the SALCA-SQ model (Oberholzer et al. 2012) is a very detailed multi-indicator model focused on intrinsic soil properties and threats to soil functions for, until now, local application in Switzerland (Vidal Legaz et al. 2017). In the light of these considerations, recently, the "Global LCIA guidance" (GLAM) run by the Life Cycle Initiative and hosted by UN Environment, recommended the soil organic carbon deficit potential as interim recommendation for soil quality (Frischknecht and Jolliet 2019). The initiative is seeking improvement through integrative soil quality scoring and modelling able to provide characterisation factors at smaller geographical scale. For a thorough and authoritative review on land use model evaluation, please refer to the work of Sala and co-authors (Sala et al. 2019).

Among the characterization models for land use impact calculation, LANCA ${ }^{\circledR}$ was selected for the Environmental Footprint - pilot and transition phase - for soil impact assessment (European Commission 2017) because it has been deemed complete in terms of scope, respondent to the ILCD/EF flows and more applicable with respect to other models. However recommended, it has to be applied "with caution", the method being classified at level III, in accordance to the Environmental Footprint definitions.

The LANCA ${ }^{\circledR}$ model (Bos et al. 2016) is a multiindicator model: it accounts for 5 different soil functions covering a sufficiently wide range of ecosystem services: erosion resistance, mechanical filtration, physicochemical filtration, groundwater regeneration and biotic production. These indicators are quantified with calculation processes based on a combination of different already-existent submodels. LANCA ${ }^{\circledR}$ developers have considered also sitespecific applications of the model. For this purpose, calculation processes for indicator quantifications are shown in LANCA ${ }^{\circledR}$ method report (Bos et al. 2016), and site-specific characterization factors (CFs) can be computed with sitespecific input data. At the same time, LANCA ${ }^{\circledR}$ provides already-computed CFs at country scale and follows a land use classification compatible with the ILCD (Vidal-Legaz et al. 2016) including 58 different land use types.

LANCA ${ }^{\circledR}$ model is still little applied in environmental studies. Vazquez-Rowe et al. (2014) automated LANCA® in the programming environment $\mathrm{R}$ to evaluate land use impacts in Luxembourg caused by maize production for energy purpose. LANCA was adopted in a multi-indicator approach to assess impacts of a small hydropower project in India (Bidoglio et al. 2019) and of breakfast cereals (Jeswani et al. 2018). More relevant to this work are studies pursuing a critical approach with the purpose to improve and document the method application. Saad et al. (2013 and 2011) highlighted a general need for regionalization of soil impact assessments by computing land use CFs for various ecosystem classes at different biogeographical scales using the LANCA $®$ calculation processes. Bos et al. (2020) calculated region-specific characterization factors in a GIS environment yielding a map with values for mechanical filtration and physicochemical filtration per grid cell for various land use types. Thoumazeau and co-workers (2019) assessed LANCA ${ }^{\circledR}$ applicability for CF calculation in Thailand and Brazil for different land use types, in data-limited conditions, and evaluated the accessibility of the method to practitioners and tested the validity of the empirical equations.

In the wake of these studies, this work aims to test the LANCA $®$ applicability at site-specific conditions. For this purpose, an area in Emilia-Romagna (North Italy) is used as a test bench to document the implementation steps and compare site-specific against country default values. Generally, the study aims at evaluating the applicability of the method to make results replicable and reliable. This implies the calculation of the soil quality levels and related CFs at site-specific conditions. The application of the Soil Quality Index and aggregation of the category indicators are out of scope.

\section{Materials and methods}

\subsection{LANCA $^{\circledast}$ model: a brief framework}

\subsubsection{Characterization factors}

The LANCA® (LANd use indicator value CAlculation) model was developed to quantify soil quality impacts caused by different land use types (Bos et al. 2016; De Laurentiis et al. 2019; Vidal-Legaz et al. 2016). The latest version of the documented method is LANCA® 2.0 while the latest characterisation factors are LANCA ${ }^{\circledR} 2.5$ (Horn, Maier 2018). LANCA® provides land use CFs to be implemented 
Table 1 LANCA $®$ indicators, characterization factors with related units, models and ecosystem services. The related areas of protection are invariantly human health and ecosystem quality for all Cfs

\begin{tabular}{|c|c|c|c|c|}
\hline Indicator & Abbreviation & Characterisation model & CFs name & CF Unit \\
\hline Erosion resistance & ER & $\begin{array}{l}\text { Water erosion potential based on the } \\
\text { revised universal soil loss equation } \\
\text { (RUSLE), (Bos et al. 2016) }\end{array}$ & Erosion potential & $\mathrm{kg} \mathrm{m}^{-2} \mathrm{a}^{-1}$ \\
\hline Mechanical filtration & MF & $\begin{array}{l}\text { Permeability determination (Beck et al. } \\
\text { 2010) }\end{array}$ & Infiltration reduction potential & $\mathrm{m}^{3} \mathrm{~m}^{-2} \mathrm{a}^{-1}$ \\
\hline Physicochemical filtration & $\mathrm{PF}$ & $\begin{array}{l}\text { Effective cation exchange capacity } \\
\text { determination (Beck et al. 2010) }\end{array}$ & $\begin{array}{l}\text { Physicochemical filtration reduction } \\
\text { potential }\end{array}$ & $\mathrm{cmol} \mathrm{kg}^{-1}$ \\
\hline Groundwater regeneration & GR & Hydrogeological balance & $\begin{array}{l}\text { Groundwater regeneration reduction } \\
\text { potential }\end{array}$ & $\mathrm{m}^{3} \mathrm{~m}^{-2} \mathrm{a}^{-1}$ \\
\hline Biotic production & $\mathrm{BP}$ & Biotic production (Beck et al. 2010) & Biotic production loss potential & $\mathrm{kg} \mathrm{m}^{-2} \mathrm{a}^{-1}$ \\
\hline
\end{tabular}

in Life Cycle Assessment studies and to be used in LCA software (Baitz et al. 2011; Saad et al. 2011). Further specifications and updates can be found in a recent work of Bos and co-workers (Bos et al. 2020), in the explication of the method and its refinements (De Laurentiis et al. 2019) and in Annex 5 of the supplementary method.

CFs express the alteration potential of the soil quality level that a land use type can cause with respect to a selected reference situation. Thus, $\mathrm{CF}$ values stand for an ecosystem quality difference $(\Delta \mathrm{Q})$ between a given reference situation $\left(Q_{\text {ref }}\right)$ (see Sect. 2.1.3) and the chosen land use situation $\left(Q_{\mathrm{LU}}\right)$ :

$C F=\Delta Q=Q_{r e f}-Q_{L U}$

Hence, $Q_{r e f}$ and $Q_{L U}$ represent an ecosystem soil quality level in absolute terms.

From a Life Cycle Thinking perspective, land use causes two different types of impacts: the transformation impact and the occupation impact. Transformation refers to the operation of human-induced change of environmental and ecological properties of the studied area, in order to pass from one land use or land cover type to a new one. The transformation is supposed to happen in a negligible time interval. Following SETAC Pellstone Workshop (UNEP 2019), LANCA $®$ distinguishes reversible and permanent transformation impacts. Occupation consists of the use-phase of the transformed area. During occupation, soil properties, and consequently the quality level, are maintained in their human-induced state. In this way, the natural regeneration phase that will bring soil quality to its original value is postponed. These distinctions are not relevant with respect to the goal of this work.

\subsubsection{Soil quality indicators and calculation processes}

In order to aim at a comprehensive soil quality consideration by looking at its multifunctional nature, LANCA ${ }^{\circledR}$ focuses on 5 different soil functions: erosion resistance, mechanical filtration, physicochemical filtration, groundwater regeneration and biotic production. Each soil function is measured by a specific indicator, uses a specific model and is mapped to an area of protection (Table 1): see for comparison and flow nomenclature Sala and co-workers (2019) and UNEP/ SETAC Life Cycle Initiative (2021) and additional information in the Supplementary Material (Annex 5). ${ }^{1}$

In this work, the soil quality level of $1 \mathrm{~m}^{2}$ of a land use type $\left(Q_{L U}\right)$ is determined following the names, methods and units reported in Table 1 and compared with the soil quality level $\left(Q_{r e f}\right)$ of $1 \mathrm{~m}^{2}$ of the reference situation to obtain the CF. In line with UNEP-SETAC recommendations (Koellner et al. 2013a, b), a positive CF value indicates a decline in ecosystem quality, i.e. the chosen land use impact leads to a decline in the performance of soil functions. On the contrary, CFs with negative sign stand for an improvement of soil quality, while a zero value proves that no alteration has been caused by the selected land use type except for erosion resistance potential where a negative erosion resistance potential stands for soil quality decrease (Saad et al. 2011; Bos et al. 2016). Table 2 better focuses on the meaning conveyed by soil quality levels and related CFs for each indicator; ecosystem services are here associated on the basis of the recent work of Bos and coworkers (2020) and ongoing UNEP/SETAC Glam3 “scoping document” (2021).

\subsubsection{Site-specific and country-averaged approaches}

LANCA® model can be used for life cycle studies by using (a) country and global average characterisation factors and (b) site-specific CFs (Bos et al. 2016, 2020). In the former case,

\footnotetext{
1 The current characterisation model refers to Bos et al. (2016) as implemented by Bos et al. (2020), and the corresponding units of measure are $\mathrm{mol} / \mathrm{m}^{2}$ as requested by ILCD/EF (Zampori and Pant 2019)
} 
Table 2 Description of the measure of the soil quality level and implied significance when the characterisation factor is positive; "reduced" and "increased" are switched for negative characterisation factors

\begin{tabular}{lll}
\hline Indicator & Soil quality level $\mathbf{Q}\left(\boldsymbol{Q}_{L U}, \boldsymbol{Q}_{\text {ref }}\right)$ & $\mathbf{C F}>\mathbf{0}$ (ecosystem services) \\
\hline ER & Mass of potentially loss soil due to water erosion & $\begin{array}{c}\text { Reduced erosion (increased erosion regulation potential) } \\
\text { Reduced permeability (reduced purification potential and supporting eco- } \\
\text { system services) }\end{array}$ \\
PF & Volume of water potentially infiltrated into soil & $\begin{array}{c}\text { Reduced physicochemical filtration capacity potential (reduced purification } \\
\text { potential and acidity regulation) }\end{array}$ \\
GR & $\begin{array}{c}\text { Total amount of cations that a mass of soil can adsorb } \\
\text { in an exchangeable form }\end{array}$ & $\begin{array}{l}\text { Reduced groundwater regeneration } \\
\text { (reduced freshwater regulation potential and climate regulation) }\end{array}$ \\
BP & Mageneration in a hydrologic balance & $\begin{array}{c}\text { Reduced primary production (reduced biotic production, food provision, } \\
\text { climate regulation) }\end{array}$ \\
\hline
\end{tabular}

LANCA ${ }^{\circledR}$ presents 5 default $\mathrm{CFs}$, related to the previously mentioned 5 indicators, for 58 different land use types (described in Koellner 2013a), on global scale at both country and world resolution (Horn and Maier 2018). In the later approach, LANCA® provides calculation processes to compute site-specific CFs. The calculation processes of quality indicators related to the 5 soil functions and the list of input data corresponding to the parameters that LANCA $®$ requires are illustrated in Supplementary Material (Annex 1). Calculation processes are from LANCA® method report (Bos et al. 2016) that illustrates the 2.0 version of the model; updates and additional indications have been introduced through the LANCA authors' recent work (Supplementary Material - Annex 5).

\subsubsection{Reference situation}

The reference situation represents a land use situation whose soil quality level is taken as baseline to measure soil quality variation caused by a certain land use type (see Eq. 1) (Saad et al. 2011, 2013; Bos et al. 2016). Thus, CF values strictly depend on the reference situation choice. Nevertheless, a general agreement about how to select the more appropriate reference situation has not been reached yet in the community of practitioners.

As recommended by Milà Canals et al. (2007) and Koellner et al. (2013a, b), LANCA® defines the reference situation as the land cover type that would be present in the studied site if no anthropogenic influence would have ever been applied. This totally uninfluenced land cover type is known as potential natural vegetation (PNV). ${ }^{2}$ It has to be stressed that the reference situation is an actual land where all input data, such as those illustrated in Table 3, should be available to be processed in the calculation structure. For this reason for the calculation of country-specific default CFs, LANCA® 2.5 calculates the soil quality level of the

\footnotetext{
2 When no information about space resolution is provided by the data source, space resolution has been calculated as the square root of the rate between regional surface $\left(22,453 \mathrm{~km}^{2}\right)$ and the number of spatially differentiated data of the given input.
}

country-specific reference situation as the mean of the soil quality levels of all the PNV in the country (for more details, see De Laurentiis et al. 2019). This approach could also be referred to as the "non-use of the same land" default reference (Saad et al. 2013). However, especially to calculate the site-specific CFs, LANCA ${ }^{\circledR}$ allows for using a recent land use situation as alternative reference situation. The latter was the adopted solution in this work. ${ }^{3}$

\subsection{Case study}

Site-specific conditions are referred to those in the EmiliaRomagna region (Italy) and specifically referred to "multiple crop" that is the most widespread land use in this region. The Emilia-Romagna region was selected as a case study area for relevance and data availability, knowledge of the area and capacity to easily access local and regional data.

\subsubsection{CF calculation}

A multiple crop cultivated area has been sampled from the regional land use map (Emilia-Romagna 2018), and the necessary input data have been collected in order to calculate the $5 \mathrm{CFs}$. The reference situation has been identified in the Mesola wood. It is a small, protected area on the north-eastern part of the Emilia-Romagna region. The Mesola wood is mainly composed by deciduous and coniferous trees. In line with FAO ecological zones (FAO 2012), the Mesola wood can be considered the local potential natural vegetation (PNV), representative of the one that, centuries ago, completely covered the Po Valley before deep anthropic alterations. For this study, LANCA® calculation processes as detailed in Bos et al. (2016) have been automated in Matlab. Table $2 S$ in Supplementary Material (Annex 1) reports the list of the input data values for the Mesola wood and the multiple-crop cultivation.

\footnotetext{
${ }^{3}$ Estimated with the Van Bemmelen factor (1.74 times the soil organic carbon (SOC)).
} 
Table 3 Collected input data for CFs calculation in the Emilia-Romagna region

\begin{tabular}{|c|c|c|c|c|c|}
\hline & Source & Space resolution & $\begin{array}{l}\text { Temporal } \\
\text { coverage }\end{array}$ & Spatial coverage & File type \\
\hline Clay content & LUCAS topsoil data & $14 \mathrm{~km}$ & 2009 & EU-27 & Excel table \\
\hline Silt content & LUCAS topsoil data & $14 \mathrm{~km}$ & 2009 & EU-27 & Excel table \\
\hline Very fine sand content & Regional geological service & $8 \mathrm{~km}$ & - & Region & Website \\
\hline Gravel content & LUCAS topsoil data & $14 \mathrm{~km}$ & 2009 & EU-27 & Excel table \\
\hline Structure class & ESDAC & $1 \mathrm{~km}$ & 2006 & EU-27 & Raster file \\
\hline Organic matter content & LUCAS topsoil data & $14 \mathrm{~km}$ & 2009 & EU-27 & Excel table \\
\hline Humus content & Estimated as the $1.75 \%$ of the organic matter content & $14 \mathrm{~km}$ & 2009 & EU-27 & Excel table \\
\hline $\mathrm{pH}$ & LUCAS topsoil data & $14 \mathrm{~km}$ & 2009 & EU-27 & Excel table \\
\hline Annual precipitation & Regional environmental protection agency & $8 \mathrm{~km}$ & 2018 & Region & Excel table \\
\hline Annual wet days & Regional environmental protection agency & $8 \mathrm{~km}$ & 2018 & Region & Excel table \\
\hline Annual evapotranspiration & NASA Earth Observing System & $500 \mathrm{~m}$ & 2017 & World & Raster file \\
\hline Groundwater distance & Regional environmental protection agency & $5 \mathrm{~km}$ & 2017 & Region & Excel table \\
\hline Mean elevation $[\mathrm{m}]$ & National environmental protection institute & $20 \mathrm{~m}$ & - & Region & Raster file \\
\hline Slope $[\%]$ & From mean elevation elaboration & $20 \mathrm{~m}$ & - & Region & Raster file \\
\hline C-factor & ESDAC & $100 \mathrm{~m}$ & 2010 & EU-27 & Raster file \\
\hline P-factor & ESDAC & $1 \mathrm{~km}$ & 2010 & EU-27 & Raster file \\
\hline Land use type & Regional geological service & $1: 50000$ & 2018 & Region & Shapefile \\
\hline
\end{tabular}

\subsubsection{SA}

The effect of changes in the model's input on the 5 soil indicators output calculation has been assessed by carrying out a sensitivity analysis (Saltelli 2002) of the LANCA®. The aim was to evaluate which inputs deserve a more accurate measurement and, conversely, which one has negligible effect on the results. The SA has been carried out with Matlab. LANCA $®$ inputs refer to the numeric and categorical information that the user is supposed to provide for the model functioning (Table 3). The input parameter space has been sampled following the probability distribution of the data observed in the Emilia-Romagna region (see Supplementary Material, Annex 5). While the target input is varied, the other inputs are kept fixed to their value in the reference situation, i.e., the Mesola wood.

The performed sensitivity analysis is a one at a time (OAT) method. It consists in varying each LANCA $®$ input, one by one, keeping the other input fixed on a baseline value. The corresponding alteration of the model output (the 5 indicators) has been observed and illustrated. For a more efficient graphical comparison, variation range of inputs data has been re-scaled to a 0 to 1 scale, according to Eq. 2 :

$\frac{x_{i}-x_{\min }}{x_{\max }-x_{\min }}$

where $x_{i}$ is the input data value, while $x_{\max }$ and $x_{\min }$ are maximum and the minimum value of the input data.
The SA of the land use input, due to its categorical nature, required the conversion from the land use classification system adopted by the land use map of the regional information provider (Emilia-Romagna) to the one adopted by the LANCA calculation processes. The former is very accurate and distinguishes 1017 different land use types; hence, due to the impossibility of automatizing the conversion, only the 100 most spread land use types in Emilia-Romagna (covering the $65 \%$ of the regional surface) have been considered in the land use SA.

\subsubsection{Evaluation of the LANCA ${ }^{\circledR}$ applicability}

For an accurate and detailed analysis of the model applicability, each calculation process for soil quality indicators quantification has been divided into individual steps (fully reported in Annex 1). The steps represent an input data selection, or the application of a formula, or the selection of a certain parameter or factor inside the calculation processes as fully explained in Annex 4. A total of 42 individual steps have been identified: 21 for erosion resistance, 10 for mechanical filtration, 7 for physicochemical filtration, 3 for groundwater regeneration and 1 for biotic production.

The LANCA $®$ applicability in a site-specific case study has been evaluated from three main criteria, as described below.

Input data requirements for site-specific $\mathrm{CF}$ calculation: amount of required input data, the extent of their 
heterogeneity and quality, the extent of the difficulty in collection and conversion for use in the model.

The arbitrariness of the user in the application of the method: the application has been judged arbitrary when the calculation depends in whole or in part on the practitioners' ability to cope with the lack of instructions and guidance.

Transparency: the arbitrariness score can take the following values:

1. If the method defines how to carry out the step and in which conditions; if units of measurement of the required input data are reported; if data sources for the characterisation model are reported and accessible

2. If LANCA® defines how to carry out the step not specifying in which conditions, or if its validity limits (i.e. parameters space and calibration) or units of measurement of the required inputs are not reported; literature is reported and accessible

3. If LANCA $®$ defines how to carry out the step not specifying in which conditions, or if its validity limits (i.e. parameters space and calibration) or units of measurement of the required inputs are not reported; literature is not reported or scarcely accessible (it is grey literature, retrieved from local catalogues and not in English)

4. If LANCA® does not define how to carry out the step and no literature is reported

Even though there is a conceptual superposition between arbitrariness and transparency, the two applicability measures are measured through different criteria (Supplementary Materials-Annex 4).

\subsubsection{Data collection}

The following Table 3 reports information about data collected for LANCA ${ }^{\circledR}$ application in the case study. Collected data are spatially differentiated at regional level, corresponding to level NUTS 2 of the European statistical nomenclature. Eight input data (organic matter content, humus content, annual precipitation, annual wet days, annual evapotranspiration, groundwater distance, slope, land use) have to be pre-processed to be correctly used in the model (see Supplementary Material, Annex 3).

\section{Results}

\subsection{Multiple-crop CFs in Emilia-Romagna}

Table 4 shows the soil quality levels $(Q)$ for the reference situation "Mesola wood" and for the land use type multiple crop and the resulting CFs. The soil quality related to PF shows an improvement in the multiple crop land use with respect to the reference situation, while all other soil quality levels - related to ER, MF, GR, BP - decline.

\subsection{Sensitivity analysis}

The variation of the 5 indicators due to changes in one of their respective data model inputs is shown in Figs. 1, 2, 3, $4,5,6$, and 7. Since the variation of parameters (re-scaled in accordance with Eq. 3) in SA reflects their observed probability distributions, a higher density of points in the plot indicates more probable values for that variable in the study case. Y axes report the indicators values.

The influence of land use type input on the correspondent indicator is individually plotted where land use is required in the model (Figs. 3 and 6). Land use distribution in the case study is interpreted as frequency. The LANCA® 2.0 land use type denomination system is adopted here. The result of the analysis for each input data on the respective indicator is fully reported and documented in the Supplementary Material (Annex 2, 3).

\subsection{Applicability}

\subsubsection{Required input data}

LANCA $®$ requires 17 input data (see table $1 \mathrm{~S}$ in Supplementary Material, Annex 1) that the user is supposed
Table 4 Soil quality levels and CF values for the reference situation and the current land use type. Units of measurement have been converted to the ones adopted by LANCA $® 2.5$, except for physicochem-

\begin{tabular}{lcllcc}
\hline $\begin{array}{l}\text { Soil quality levels }(\mathrm{Q}) \text { for } \\
\text { each indicator }\end{array}$ & $\begin{array}{l}\text { Erosion resistance } \\
\left(\mathrm{kg} \mathrm{m}^{-2} \mathrm{a}^{-1}\right)\end{array}$ & $\begin{array}{l}\text { Mechanical filtration } \\
\left(\mathrm{m}^{3} \mathrm{~m}^{-2} \mathrm{a}^{-1}\right)\end{array}$ & $\begin{array}{l}\text { Physicochemi- } \\
\text { cal filtration } \\
(\mathrm{cmol} \mathrm{kg})\end{array}$ & $\begin{array}{l}\text { Groundwater regeneration } \\
\left(\mathrm{m}^{3} \mathrm{~m}^{-2} \mathrm{a}^{-1}\right)\end{array}$ & $\begin{array}{l}\text { Biotic production (kg } \\
\left.\mathrm{m}^{-2} \mathrm{a}^{-1}\right)\end{array}$ \\
\hline $\begin{array}{l}\text { Mesola wood }\left(Q_{r e f}\right) \\
\text { Multiple-crop }\left(Q_{L U}\right)\end{array}$ & $\begin{array}{l}5.762 * 10^{-5} \\
1.12 * 10^{-3}\end{array}$ & 18.2 & 6 & 0.03 & 1.42 \\
$\begin{array}{l}\text { Resulting CF values for multiple-crop land use } \\
\text { Multiple-crop }\end{array}$ & $-1.06 * 10^{-3}$ & 12.7 & -11 & -0.19 & 0.65 \\
\hline
\end{tabular}

ical filtration compliant to LANCA® 2.3 units. Compare to Table 2 for a description of the terms 


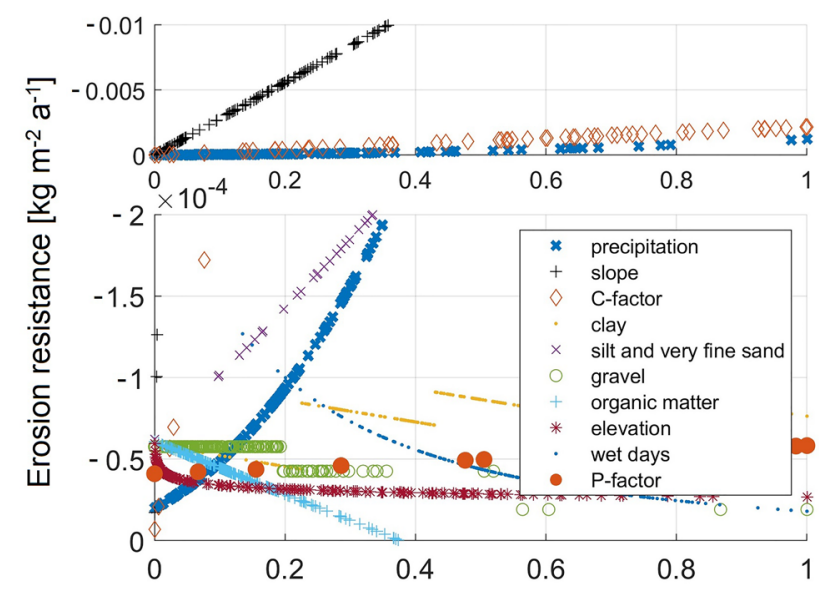

Fig. 1 Sensitivity of the erosion resistance to the model input parameters. Data density reflects observed distribution in the study area. Input data ranges have been rescaled in a $0-1$ interval. The lower section shows an amplified $\left(* 10^{-4}\right)$ scale of the values. The negative sign in the $Y$ axis indicates the measure of erosion potential as opposite to erosion resistance

to collect and implement in the model: 16 are numerical and 1 is categorical (i.e. land use type). The 17-input data refer to 4 different fields: pedology (clay, silt, very fine sand, organic matter, gravel and humus contents, structure class, $\mathrm{pH}$ ), hydrogeology (groundwater distance, annual precipitations, annual wet days, annual evapotranspiration, surface runoff), geomorphology (elevation, slope), land use (C-factor, P-factor and land use type). Three types of difficulties have been encountered during the data collection phase. First, the adopted sources provide data in a different form or unit of measurement from the ones requested by

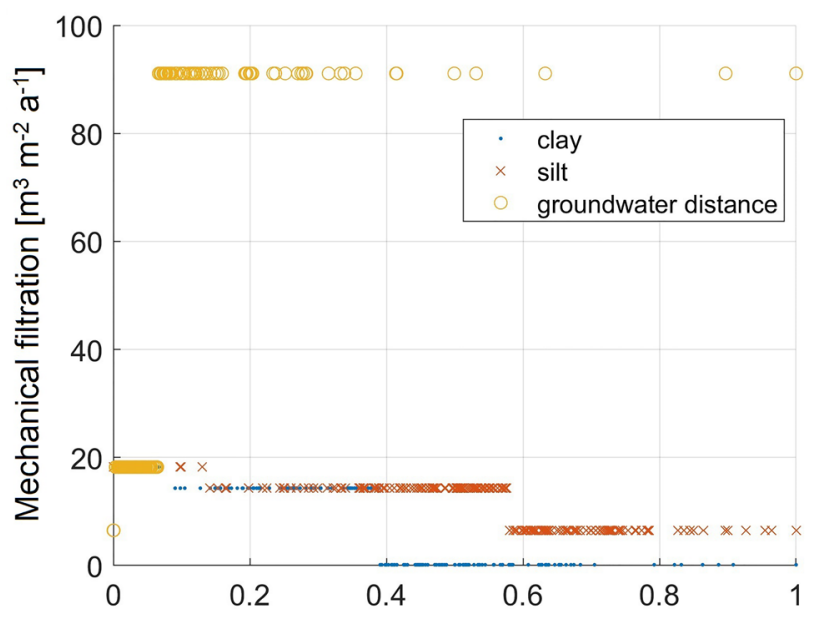

Fig. 2 Data model inputs influence on the soil quality level associated to mechanical filtration (MF). Data density reflects observed distribution in the study area
LANCA® (for 5 request input data out of 17 ); thus, raw data, for the regional CFs calculation, had been elaborated before model implementation (see Supplementary Material, Annex 3, for detailed explanation of input data elaborations). Second, humus content was not available for the case study; therefore, it has been estimated according to literature. A marginal note: soil structure class was available; however, its regional distribution, required for the SA, was not. Clay and silt content are requested by LANCA ${ }^{\circledR}$ with two different definitions: mass of eroded soil and CECeff calculations follow the USDAC definitions and textural classification, and permeability adopts a German granulometric and texture classification. Therefore, the German classification had to be converted into the USDAC one by comparing the two respective soil texture classification triangles.

\subsubsection{User arbitrariness}

Figure 8 presents the number of discretional steps for each indicator calculation that are supposed to be completed by the user. Steps are defined discretional because they are not guided by a specific protocol, and interpretation is not common practice (see Sect. 3.1.1.3 for the definition). Globally, user arbitrariness was observed in 9 steps out of 42, and Table 3S of Supplementary Material (Annex 4) reports why these steps have been judged as arbitrary.

Moreover, it has to be considered that the selection of the reference situation for CFs calculation is, as well, up to the user.

\subsubsection{Transparency}

Figure 9 illustrates the share of transparency score for each indicator (see Sect. 3.1.1.3 for classification). Globally, about two-thirds of steps show a good level of transparency. In Table 3S of Supplementary Material (Annex 4), a fully detailed explanation of the criteria used to judge transparency is reported.

\section{Discussion}

\subsection{Site-specific characterisation factor}

In the following sections, the CFs obtained from the reference situation Mesola wood to multiple crop in the case study are discussed along with the site-specific and country default comparison. A thorough description and comment of the findings are presented in the Supplementary Material (Annex 2). 
Fig. 3 Variation of MF in relationship with the main land use types in the study area; land use frequency in logarithmic scale is expressed by colours, as shown by the colorbar on the right

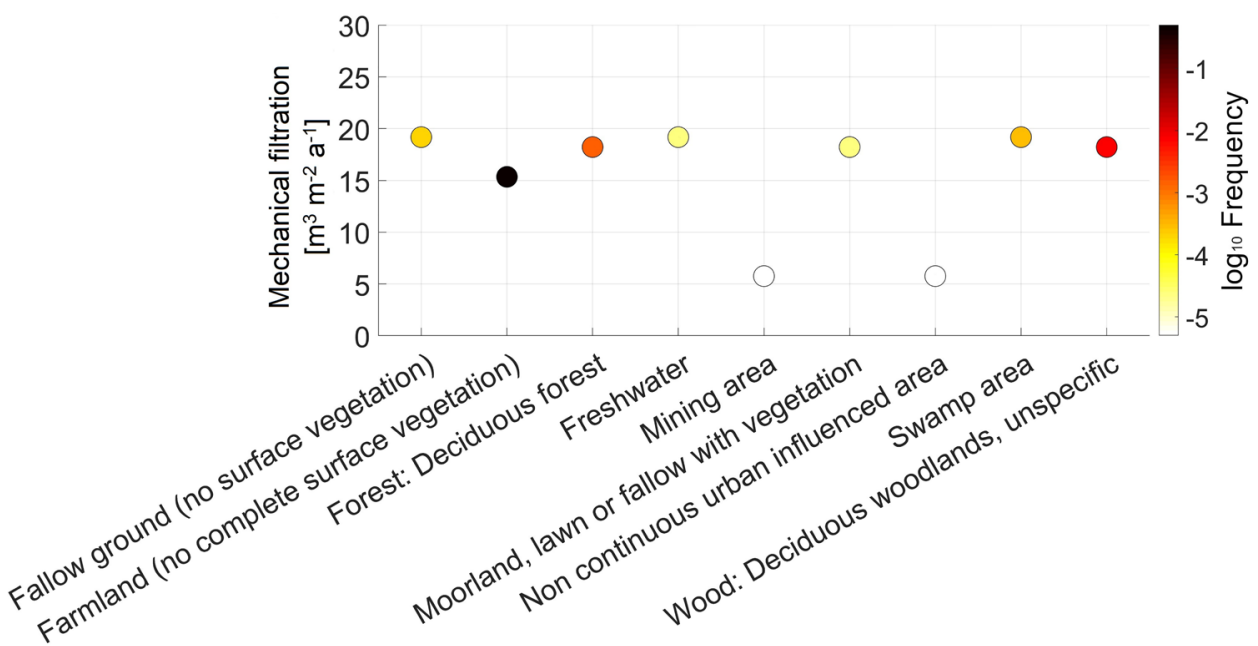

\subsubsection{Erosion resistance}

The mass of eroded soil obtained by LANCA $®$ (see Table 4) was compared to erosion values provided by ESDAC. ESDAC estimated water erosion in Europe with an updated version of the RUSLE equation (RUSLE2015) based on peer-reviewed data and obtained a high-resolution potential erosion map (Panagos et al. 2015a, b). The mean erosion values from the ESDAC map have been calculated for the same areas analysed in this study: the Mesola wood presents $0.001 \mathrm{~kg} \mathrm{~m}^{-2} \mathrm{a}^{-1}$ while multiple crop shows $0.15 \mathrm{~kg} \mathrm{~m}^{-2}$ $\mathrm{a}^{-1}$. Thus, there are 2 orders of magnitude of difference between LANCA $囚$ results $\left(5.762 * 10^{-5}\right.$ for the Mesola wood and $1.12 * 10^{-3}$ for multiple crop) and ESDAC predictions,

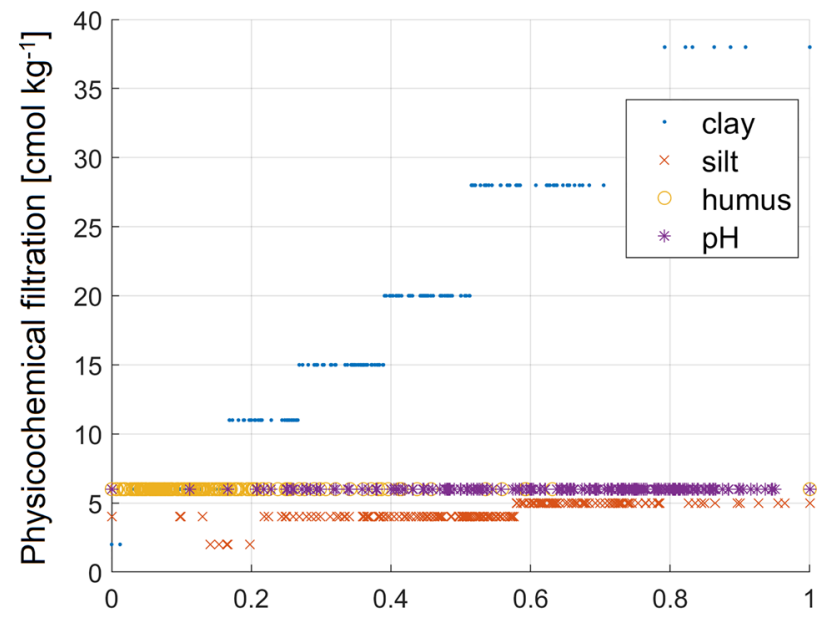

Fig. 4 Data model inputs influence on the soil quality level associated to physicochemical filtration (PF). Note the change of class related to clay content. Data density reflects the observed distribution in the study area indicating a relevant underestimation of soil loss by the RUSLE model adopted by Bos et al. (2016). The different values estimated by LANCA® may be due to the fact that calculation processes are valid only for a given range of values, depending on where the calculation processes have been calibrated (see Sect. 4.2.1).

\subsubsection{Mechanical filtration}

The reference situation $\left(Q_{r e f}\right)$ performs better than the current land use $\left(Q_{L U}\right)$ in permeability, with $18.2 \mathrm{~m}^{3} \mathrm{~m}^{-2} \mathrm{a}^{-1}$ against $5.5 \mathrm{~m}^{3} \mathrm{~m}^{-2} \mathrm{a}^{-1}$. The only critical aspect differentiating the two soils is texture: a low clay content in the Mesola wood makes the water infiltration faster than in multiple crop, which has a sandy-clay-loam texture; as shown in Fig. 2, a poorer clay content leads to a lower mechanical filtration capacity.

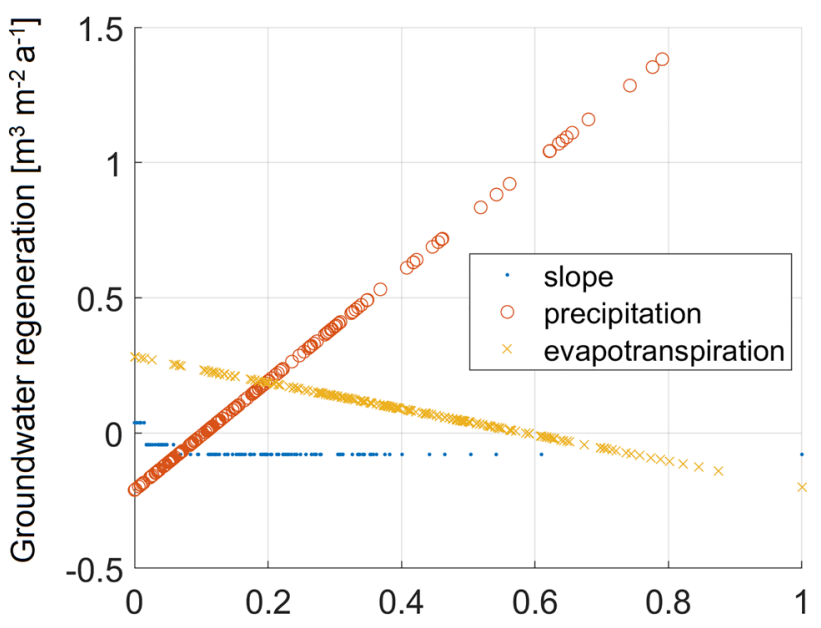

Fig. 5 Data model inputs influence on the soil quality level associated to groundwater regeneration (GR) 
Fig. 6 Variation of GR in relationship with the main land use types in the study area; land use frequency in logarithmic scale is expressed by colours, as shown by the colorbar on the right

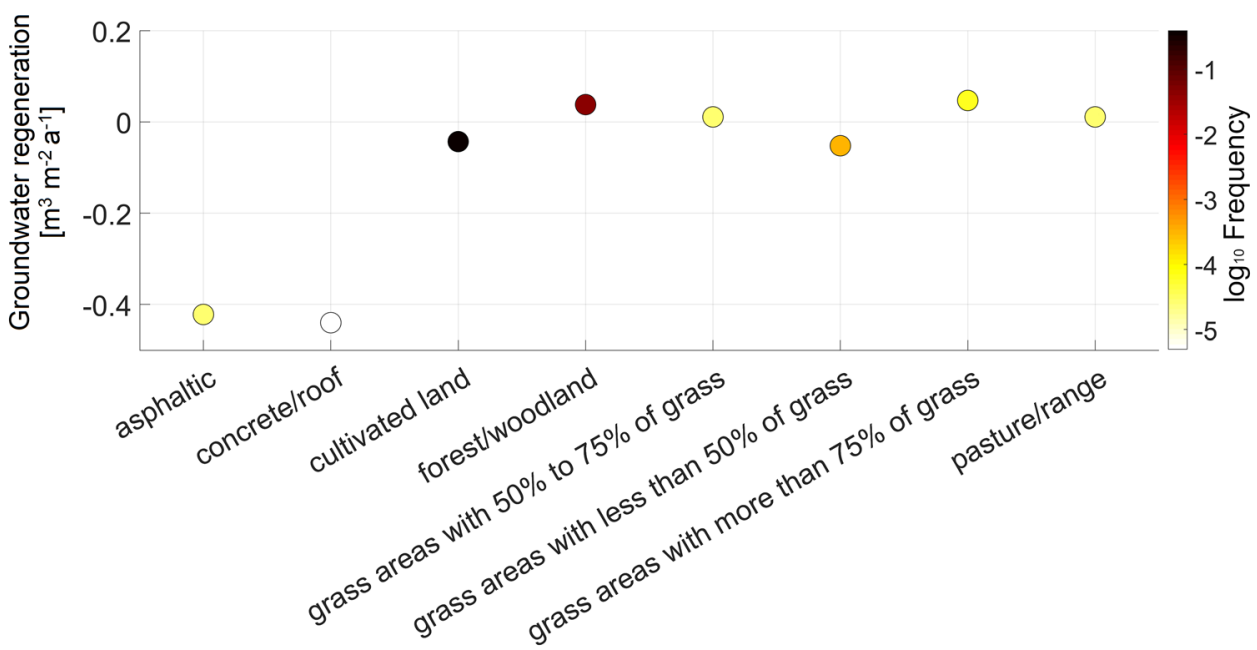

\subsubsection{Physicochemical filtration}

$\mathrm{PF}$ is also influenced by the differences in texture; the value is larger in the multiple crop than in the reference situation. In fact, the multiple crop soil has a higher clay content, and this leads to a better physicochemical filtration capacity than the Mesola wood. The sealing factor calculation was not applied here because clear instructions on that were lacking. This consideration converges with the one formulated also by Thoumazeau and collaborators (2019). Since no clear calculation process was indicated, the sealing factor was not considered in the physicochemical filtration indicator.

\subsubsection{Groundwater regeneration}

The factor mainly responsible for the difference in infiltrated water between the Mesola wood $\left(0.03 \mathrm{~m}^{3} \mathrm{~m}^{-2} \mathrm{a}^{-2}\right)$ and multiple crop $\left(-0.19 \mathrm{~m}^{3} \mathrm{~m}^{-2} \mathrm{a}^{-2}\right)$ is the annual precipitation. Despite the two studied areas being only about $60 \mathrm{~km}$ apart, the observed annual precipitation in the Mesola wood is $300 \mathrm{~mm} \mathrm{a}^{-1}$ higher than in multiple crop area. On the other hand, evapotranspiration rate and surface runoff are similar between the areas.

\subsubsection{Biotic production}

The biotic production loss potential for multiple crop in Emilia-Romagna is $0.77 \mathrm{~kg} \mathrm{~m}^{-2} \mathrm{a}^{-1}$ : LANCA $®$ states that converting a woodland to multiple crop cultivation reduces NPP from 1.42 to $0.65 \mathrm{~kg} \mathrm{~m}^{-2} \mathrm{a}^{-1}$.

\subsubsection{Multiple crop CFs: site-specific versus country-default values}

Table 5 allows a comparison between multiple crop CFs for Emilia-Romagna and Italian CFs provided by LANCA® 2.5.

As it is possible to observe, 3 out of 5 regional CFs differ significantly. It is noteworthy that $\mathrm{ER}$ and $\mathrm{PF}$ in the site-specific calculation are negative values, while the country-default values
Fig. 7 Variation of BP in relationship with the main land use types in the study area; land use frequency in logarithmic scale is expressed by colours, as shown by the colorbar on the right

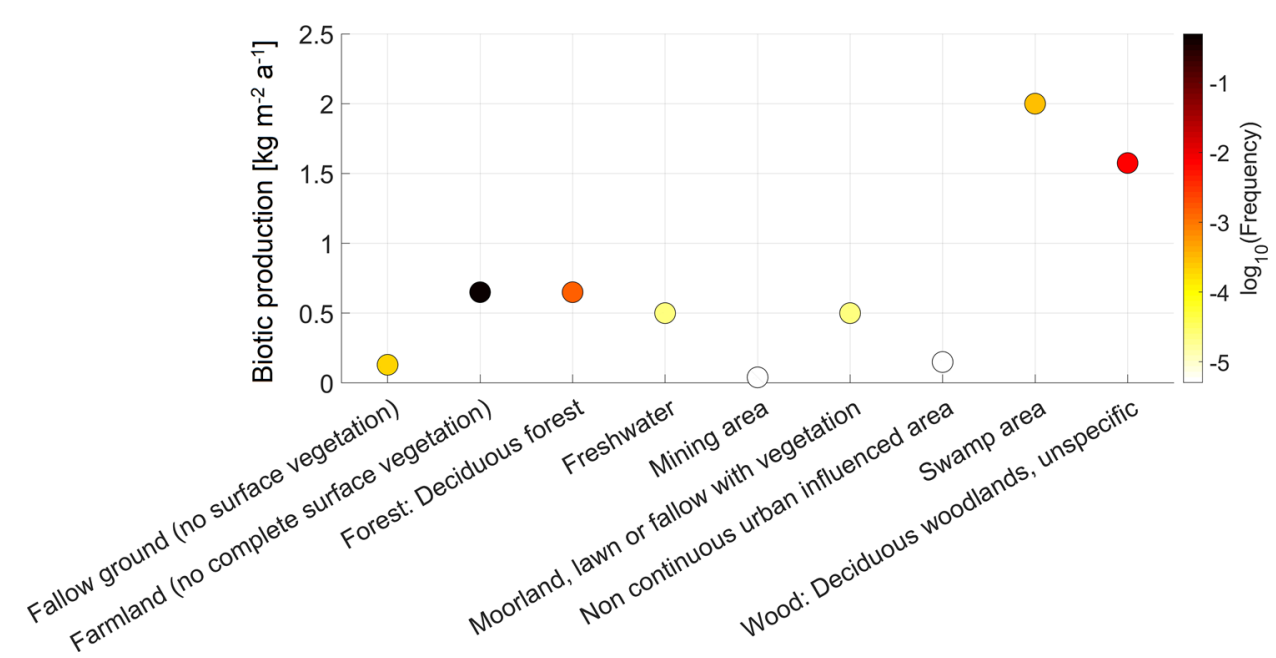




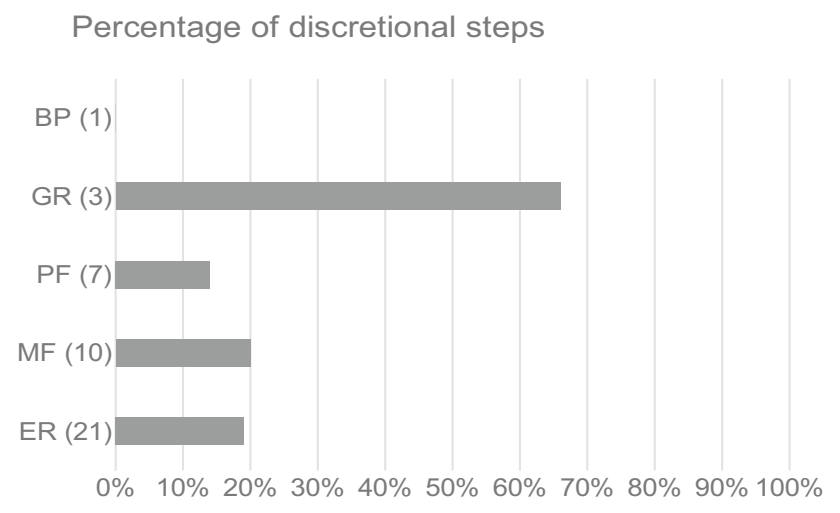

Fig. 8 Percentage of calculation steps, for each indicator that has been evaluated as discretional. The total number of steps of each indicator is reported in parenthesis

are positive. GR values strongly diverge. On the contrary, MF and BP display convergent values. Divergence cannot be explained. Not knowing which datasets were used by LANCA® to calculate world and country-default characterisation factors, the possibility to explore the causes of such a great difference between countrydefault and site-specific CFs is precluded. More precisely, it cannot be found out if these differences are due to the adopted input values, to the choice of the reference situation, or to other aspects due to user arbitrariness.

\subsubsection{Influence of the reference condition}

When carrying out a regionalised life cycle impact assessment, the practitioner must define the soil quality level of the reference situation $\left(Q_{r e f}\right)$. Two options are given. The first one is to adopt country-default values as tabled in LANCA 2.5. The second option is to measure and calculate $Q_{r e f}$ as showed in this work. Saad and collaborators (2011), who applied LANCA ${ }^{\circledR}$ in Canada and studied spatially differentiated $\mathrm{CFs}$, reported a relevant variability of $\mathrm{CF}$ values, referred to the same land use, when changing the reference situation. The sensitivity analysis pointed out that some intrinsic area characteristics (pedological, geomorphological and climatic conditions) have significant influence on the indicators. This can be explained if considering that in regions that have been human dominated for centuries a reference area is rare to find, since all land with optimal characteristics for agricultural production has been already used as such, and "natural areas" are confined to land with sub-optimal characteristics. Therefore, the selected reference area can sit in a distant area where the geomorphology, climatic and pedogenic values are not comparable. The consequence is that the reference situation choice has a strong influence on the $Q_{\text {ref }}$ calculation, and alternative reference choices lead to different values, as it has been highlighted by Saad et al. (2011).

To study the influence of the reference condition on the CF determination, a third land condition is here introduced. In this exercise, Mesola wood is the original and natural situation $\left(\mathrm{REF}_{0}\right)$, multiple crop is the alternative hypothetical reference condition $\left(R E F_{h}\right)$, and maize land (arable, permanently irrigated land) is the actual land use (Fig. 10). The hypothesis is acceptable if considering that multiple crops include fodder crops, fallow land, semi-permanent crops (class 211 of the Corine land cover classes) together with heterogenous agricultural areas (class 241 "annual crops associated with permanent crops" and class 242 "complex cultivation patterns") which belongs to the secular landscape of the region (Barbera and Cullotta 2014). Maize land indicators and the consequent change of the $\mathrm{CF}$ value are obtained following the process above illustrated (Table 4). In the following, $C F_{h-L U}$ is the CF expressing the soil quality changes from multiple crops, while $C F_{0-L U}$ changes from the original Mesola wood. Maize land values were obtained from a random sampling of 4 soils in the northeast sector
Fig. 9 Percentage of calculation steps, for each indicator, with the assigned transparency scores

\section{Transparency scores}

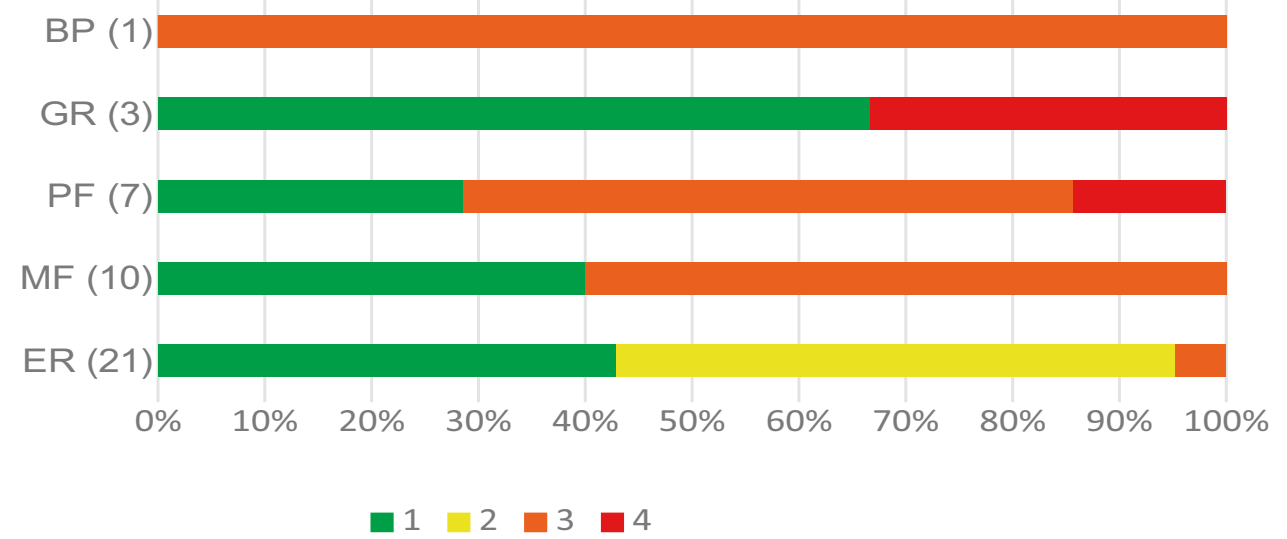


Table 5 Country-average CF provided by LANCA® 2.5 and regional CFs as calculated in Table 4

\begin{tabular}{|c|c|c|c|c|c|}
\hline & $\begin{array}{l}\text { Erosion resistance } \\
\text { potential }\left(\mathrm{kg} \mathrm{m}^{-2}\right. \\
\left.\mathrm{a}^{-1}\right)\end{array}$ & $\begin{array}{l}\text { Mechanical filtration } \\
\text { loss potential }\left(\mathrm{m}^{3} \mathrm{~m}^{-2}\right. \\
\left.\mathrm{a}^{-1}\right)\end{array}$ & $\begin{array}{l}\text { Physicochemical filtration } \\
\text { loss potential }\left(\mathrm{cmol} \mathrm{kg}^{-1}\right)\end{array}$ & $\begin{array}{l}\text { Groundwater regeneration } \\
\text { loss potential }\left(\mathrm{m}^{3} \mathrm{~m}^{-2} \mathrm{a}^{-1}\right)\end{array}$ & $\begin{array}{l}\text { Biotic production loss } \\
\text { potential }\left(\mathrm{kg} \mathrm{m}^{-2} \mathrm{a}^{-1}\right)\end{array}$ \\
\hline $\begin{array}{l}\text { Permanent } \\
\text { crops, } \\
\text { irrigated, } \\
\text { extensive } \\
\text { (Italy) }\end{array}$ & 13.1 & 12.8 & 0.027 & 0.046 & 0.657 \\
\hline $\begin{array}{l}\text { Multiple-crop } \\
\text { (Emilia- } \\
\text { Romagna } \\
\text { region) }\end{array}$ & $-1.06^{*} 10^{-3}$ & 12.7 & -11 & 0.23 & 0.77 \\
\hline
\end{tabular}

of the region, comparable to the multiple crop extension and average values reported in Table 6 . In the latter, the variation $(\Delta)$ of the $C F_{L U}$ when adopting the hypothesis (h) with respect to the original situation (0) is negligible in the case of ER, particularly relevant in the case of the MF, GR and BP.

The UNEP-SETAC Life Cycle Initiative GLAM, Vol I (Frischknecht et al. 2016) recommends to establish a rationale for the choice of the reference state according to "type", "flexibility", "rationale and constraints" and expands on the trade-off of marginal vs. average vs. linear approaches. This might be necessary and recommended in many circumstances. In the case of the land use-related impacts on biodiversity, it is suggested for example to adopt "ecoregional characterisation factors". Indeed, the UNEP-SETAC Life Cycle Initiative GLAM, Vol II (Frischknecht and Jolliet 2019) acknowledges the need for marginal characterisation factors where the reference land use is based on current land use activities. The discussion over the choice of the reference situation is also discussed and tackled by Valeria del Laurentiis (2019) who in the "limitations of the method" suggested to drive the method towards a fully integrated geographic information system (GIS)-based approach for a global raster of $1 \mathrm{~km}$ cell size and at this level to calculate the global quality map of the reference situation based on the potential natural vegetation at cell level for each indicator. This is also recalled in GLAM Vol II, where it is suggested to provide indicators at a smaller geographical scale (e.g. states, ecoregions within a country, based on the coordinates). On this basis, 3 suggestions were formulated and reported in Table 7.

\subsection{Local OAT sensitivity analysis}

The sensitive analysis applied to the data distribution in the case study highlights that annual precipitation and slope are the most influential inputs for mass of eroded soil calculation. Precipitations affect significantly also GR, while clay mainly rules the output of the PF. Hence, a precise determination of these input data is necessary for a correct quantification of local CFs. It has to be noticed that these inputs represent intrinsic soil characteristics that cannot be directly linked to the land use type. Humus, $\mathrm{pH}$ and gravel content play no significant roles in the determination, and a more approximate determination of these latter inputs could strongly reduce the required effort for LANCA application with no relevant alterations in results. The analysis of individual indicators is provided below.

\subsubsection{Erosion resistance}

The effect of slope on the modelled soil erosion is remarkable (Fig. 1) and dominates primarly the source of errors. The strict dependence between erosion and slope could also be
Fig. 10 Framework to study the influence of the reference situation on the $\mathrm{CF}$ towards an actual land use; the dashed line corresponds to the $\mathrm{CF}$ calculated in Table 4

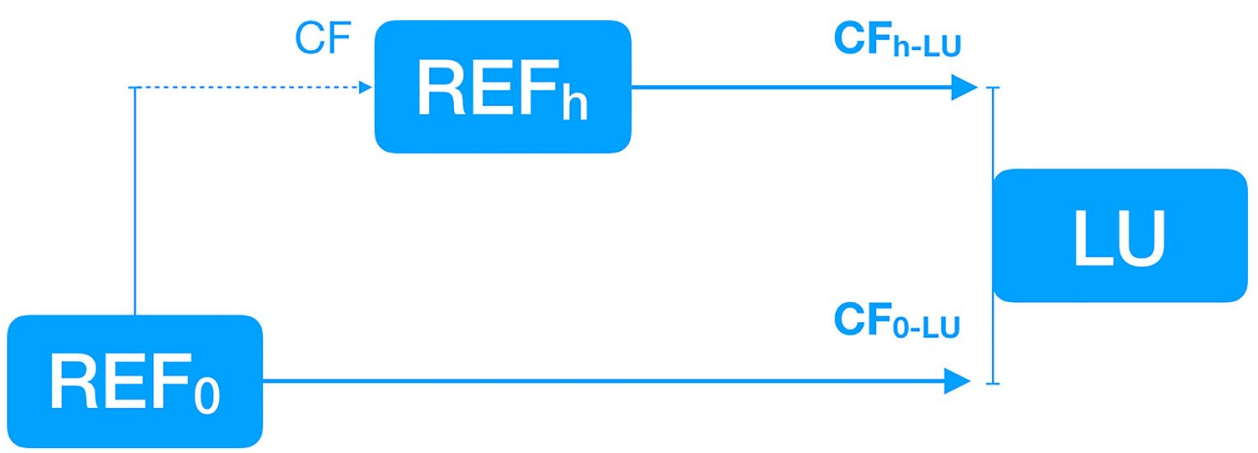


Table 6 Soil quality indicators associated to and variation of the CF value reference situation and the current land use type for the study site

\begin{tabular}{llllll}
\hline & $\begin{array}{l}\mathrm{ER}(\mathrm{kg} \\
\left.\mathrm{m}^{-2} \mathrm{a}^{-1}\right)\end{array}$ & $\begin{array}{l}\mathrm{MF}\left(\mathrm{m}^{3}\right. \\
\left.\mathrm{m}^{-2} \mathrm{a}^{-1}\right)\end{array}$ & $\begin{array}{l}\mathrm{PF}(\mathrm{cmol} \\
\left.\mathrm{kg}^{-1}\right)\end{array}$ & $\begin{array}{l}\mathrm{GR}\left(\mathrm{m}^{3}\right. \\
\left.\mathrm{m}^{-2} \mathrm{a}^{-1}\right)\end{array}$ & $\begin{array}{l}\mathrm{BP}(\mathrm{kg} \\
\left.\mathrm{m}^{-2} \mathrm{a}^{-1}\right)\end{array}$ \\
\hline$L U_{\text {Maizeland }}$ & $5.2 * 10^{-2}$ & 5.2 & 36 & -0.03 & 0,65 \\
$\Delta C F_{L U}$ & $2 \%$ & $98 \%$ & $37 \%$ & $367 \%$ & $100 \%$ \\
\hline
\end{tabular}

observed looking at the European soil erosion map developed by Panagos (Panagos et al. 2015a, b). This can be a problem when slope data are not available as is the case in some countries (Thoumazeau et al. 2019). The second more important factor is the $\mathrm{C}$-factor whose influence is discussed hereafter (Sect. 5.3.2.). Given the relation that mass of eroded soil shows with "annual precipitation" and "wet days", it is clear that soil is very susceptible to precipitation intensity (Fig. 1). Annual precipitation $\left(\mathrm{mm} \mathrm{year}^{-1}\right)$ is the measure of the total precipitation. Wet days are the total number of days where the precipitation event exceeds $1 \mathrm{~mm} /$ day (Supplementary Material, Annex 3). The erosion increases exponentially with the increase of precipitations and decreases exponentially with the increase of wet days; in fact, a small number of wet days and high amount of precipitation are related with high precipitation intensity. This feature is rapidly changing due to new climate patterns and requires a continuous update of the datasets. Another observation concerns the mass of eroded soil and elevation which is quite unexpected. Below $40 \mathrm{~m}$ a.s.l., the soil loss increases exponentially when getting closer to sea level (Fig. 1); above $40 \mathrm{~m}$ a.s.l., the elevation has negligible influence on erosion resistance. These trends have not been observed in literature. The Panagos' erosion map applied to the study sites, when compared to the related elevation map, clearly shows that soil loss trends do not follow elevation variations where the adopted LANCA ${ }^{\circledR}$ model had predicted the opposite. The particular interaction between elevation and erosion shown by LANCA ${ }^{\circledR}$ could be due to the fact that elevation values in the study site are out of the parameter space that had been considered when the specific RUSLE equation used in this study was calibrated.

\subsubsection{Mechanical Filtration}

Permeability depends on silt and clay fractions, on groundwater distance from the surface and on land use type (Bos et al. 2016). Permeability decreases as the percentage of silt and clay fraction grows. However, in this study, silt and clay have only a slight effect on permeability, while the groundwater distance from the surface can greatly increase it (Fig. 2). The rationale is that the larger the distance that water has to cover to reach the groundwater, the most will be the water suspensions that will be captured by underground soil. The trend is not linear: at the beginning, a large amount of suspension is rapidly removed, but after a certain groundwater distance, the suspension retained gets close to zero and, hence, its removal stops. Looking at Fig. 3, only soilsealing land uses, i.e. "mining area" and "non-continuous urban influenced area", substantially reduce permeability but have very low frequencies (white colour in Fig. 3). Agricultural land uses, the most common land use types, have only a small effect on permeability. This could be due to neglected effect of compaction that heavy tillage machineries have on cropping areas by LANCA $®$. Soil compaction is one of the most relevant components of soil degradation; it not only affects mechanical filtration, but it is also a strong erosion driver (Batey 2009). The topic has been thoroughly reviewed by Sonderegger and coworkers (2020) who proposed a method to determine characterisation factors for soil compaction.

\subsubsection{Physicochemical filtration}

With reference to Fig. 4, PF depends only on clay content. Clay particle surface, as well as organic matter particles, is negatively charged. Thus, cations like $\mathrm{K}^{+}, \mathrm{NH}^{4+}$, or $\mathrm{Ca} 2+$, which are fundamental for plant nutrition, are highly available in clay soils. In the present study, the cation exchange effective capacity (CECeff) is not sensitive to changes of $\mathrm{pH}$ and humus content (Orgiazzi et al. 2018; Toth et al. 2013). This is due to the homogenous values of $\mathrm{pH}$ and humus contents in the area studied. Silt content, despite having a wide variation range, has negligible effect on the output.

\subsubsection{Groundwater regeneration}

Precipitations are the main factor regulating infiltrated water (Fig. 5): high rates of rainfall lead to rainwater infiltrating into the soil without runoff generation. However, the effect of the most frequent annual precipitations ( $0-0.3$ in Fig. 5 corresponding to $600-800 \mathrm{~mm}$ a-1) is compensated by the inverse effect of annual evapotranspiration, which reduces infiltrated water with a similar but opposite trend. Slope and land use type are used to estimate runoff according to Chow et al. (1988). The former does not play a relevant role, while the unique land use types that significantly reduce infiltrated water are soil sealing land uses, i.e. "asphaltic" and "concrete/roof"; however, these land uses occupy only the $0.01 \%$ of the studied territory (Fig. 6). 


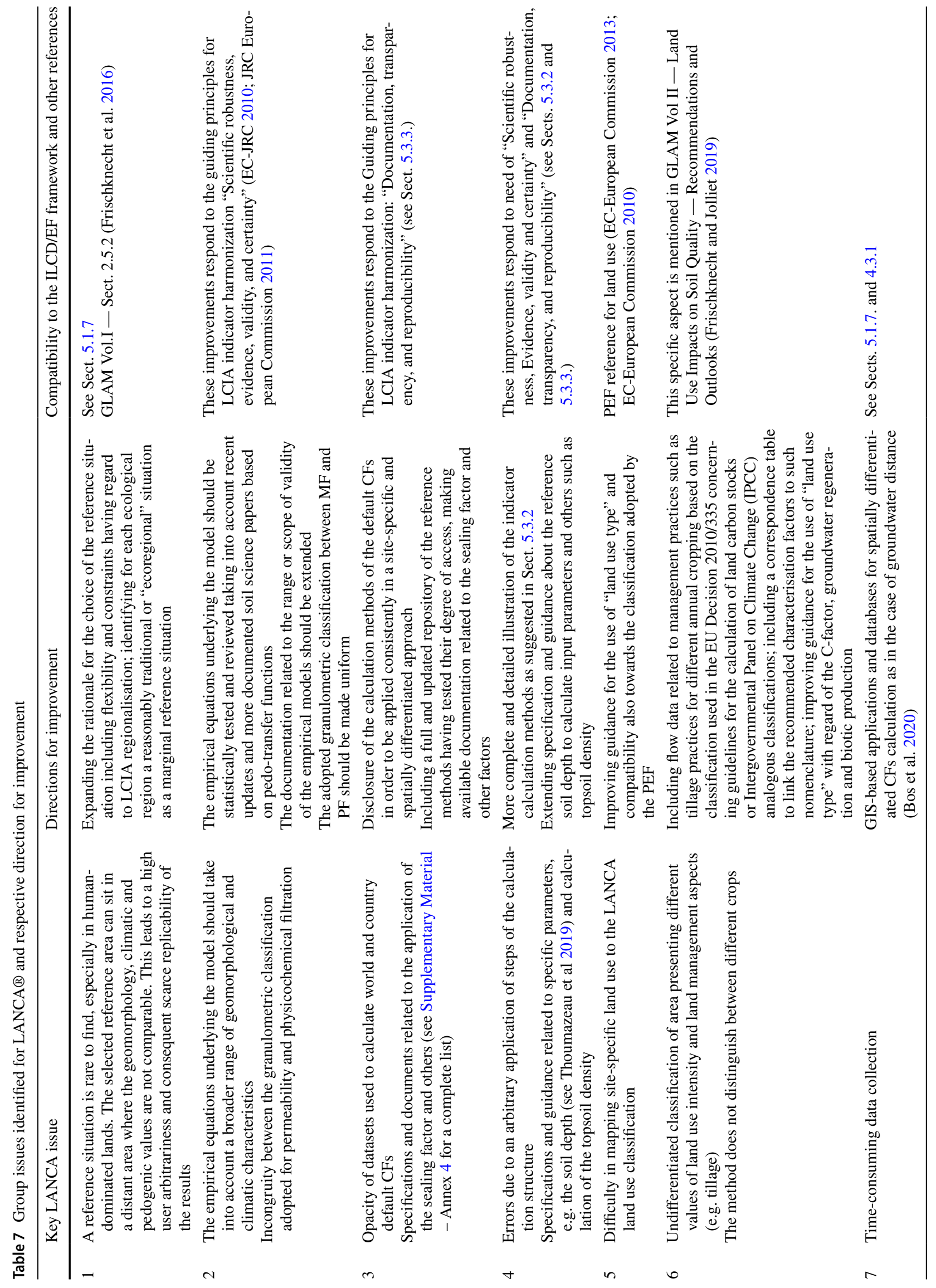




\subsubsection{Biotic production}

LANCA $®$, in the site-specific approach, proposes a coarse land use differentiation; it does not distinguish between different crops, intensive or extensive cultivation managements or other agricultural aspects such as tillage practice. Thus, the majority of land use types shows the same biotic production values: $0.65 \mathrm{~kg} \mathrm{~m}^{-2} \mathrm{a}^{-1}$ (Fig. 7). This observation converges with that of Thoumazeau and collaborators (2019) who noted a lack sensitivity of the method towards land management when comparing different land practices in Brazil and Thailand.

\subsection{Applicability}

\subsubsection{Requested input data}

The data collection was the most time-consuming activity, requiring between 30 and 40 working day. It is expected that the required time would not significantly decrease if repeating data collection in the same nation or administrative union such as the EU. Despite the local regional authority of the case study providing detailed databases with pedological, geomorphological and hydrogeological information at a good space resolution, regional datasets did not meet the entire amount of required data for $\mathrm{CF}$ calculation. The search for alternative data sources and literature data necessary to estimate the missing data (humus content and soil structure class) was time-consuming and reduced the accuracy and representativeness of the results. Given the large amount of requested data and their different origins, the collected datasets are characterised by heterogeneous units of measurements, space and time resolution and format availability (spreadsheets, PDF, raster, shape, etc.). Therefore, the user is forced to pre-process a large amount of data before LANCA ${ }^{\circledR}$ implementation (Supplementary Material - Annex 3). Vidal Legaz et al. (2017), in their land use impact model evaluation, confirmed that difficulties in accessing the input data, required for the site-specific application of LANCA ${ }^{\circledR}$, are a limitation of the model applicability. On the other hand, Bos and coworkers (2020) and Sonderegger and coworkers (2020) have specifically proposed solutions and workaround for high-resolution LCIA calculation; more extensively, Pfister and co-workers (2020) have proposed a framework for GIS-based applications. This is a cross-cutting issue in the above-mentioned GLAM.

\subsubsection{User arbitrariness}

The user choices in the application phases affect substantially the outputs. Thoumazeau's group for the application of method defined as uncertain $45 \%$ of the total input parameters of the LANCA ${ }^{\circledR}$ method in Brazil. In this work, 9 scarcely guided steps were found out of 42 . The difference with Thoumazeau's can be easily explained considering that the uncertainty due to the user arbitrariness has been distinguished from lack of transparency. As shown above (Sect. 4.2.1.), few input data can have a significant influence on land use impact evaluation. The $\mathrm{C}$-factor related to the determination of the erosion resistance (ER) is one of the most sensitive factors. LANCA® gives no specific indications about how to discriminate the appropriate landcover/ use with respect to a specific arable land use type (Panagos et al. 2015b). As an example, the C-factor varies from 0.20 to 0.38 respectively for cereals and grain maize; the class shift implies a change of the output of around 300\%; however, both classes can be assigned to arable land use classes (extensive or intensive, irrigated or not irrigated). Thus, different approaches in determining the C-factor could lead to very divergent results. Similarly, the arbitrary determination of the evapotranspiration input data could alter the infiltrated water value from $-2683 \%$ up to $+1227 \%$. In this case and other occurrences, the use of a standardized land use classification system and guidance with respect to specific arable land use classes with regard of the $\mathrm{C}$-factor assignment can make easier a uniform approach. These considerations also respond to the need of providing indicators following current knowledge rather than subjective or arbitrary choices or normative assumptions. This is a key principle in the LCIA indicator harmonisation (EC-JRC 2010; JRC European Commission 2011). Specifically with regard to land use models, this principle requires that "the model including the underlying data have a good potential for being consistently improved and further developed including and regarding geographical/emission situation and temporal differentiation".

\subsubsection{Transparency}

The transparency score of LANCA®, reported in Fig. 9, was the result of 5 checks applied to each calculation step: (i) presence of guidance, (ii) completeness in scope, (iii) indications of units of measurement and conversions of the input data, (iv) documentation and (v) degree of access to the documentation (Supplementary Materials - Annex 4).

Low scores reflect difficulties to find guidance, access to reference and indications to cope with the calculation for site-specific conditions. In this regard, it has to be noted that many characterization models adopted by LANCA ${ }^{\circledR}$ are rooted in models that have been set up through empirical studies. This means that such models potentially have limited validity in conditions not included in the model 
calibration. In other terms, the accuracy of their estimations strictly depends on the space of variables that has been considered, i.e., in which area these empirical models were initially developed and/or applied. This could lead to inaccurate results, as illustrated for the impact of elevation on the mass of eroded soil. Another example regards the K-factor equation of the RUSLE, which is not valid in soils with more than $70 \%$ of silt, as shown by Panagos et al. (2014). These conditions of validity are not explicitly declared in the method. This observation converges with those of Thoumazeau and coworkers (2019). In other cases, the required unit of measurement of an input was not reported, or the cited literature was not easy to find. As an example of such case in point, the classification of soil types is referred to the Arbeitsgruppe Bodenkunde and would have required a request to the "Senate Department for Urban Development and Housing", a part of Berlin's urban information service. Again, this finding agrees with those of the Thoumazeau and coworkers who found that literature references of the guidelines were hardly accessible and that "most of the references are under restricted access". The lack of access to documentation is an additional obstacle to a full application. For example, in the characterization models of the MF and PF, different textural classification systems are adopted without means of conversion. Finally and notably, the land use classification and the units of measurement adopted in the calculation processes (LANCA 2.0) are different from the ones used for country-default CFs proposed in the updated CF dataset LANCA ${ }^{\circledR} 2.5$, and no table of conversion is provided. An explicit guidance on this and other calculation steps (see for a full review of knowledge gaps in the Supplementary Materials - Annex 4) ensures that the scientific principles, models and data supporting the indicators are accessible to third parties and thus facilitate review and quality assurance. This is a key principle in the LCIA indicator harmonisation (EC-JRC 2010; JRC European Commission 2011) recalled in the current work of the life cycle initiative (Frischknecht and Jolliet 2019). Specifically, this principle requires that "the model documentation is published and easily accessible (incl. description of the mechanism, the model, temporal and spatial scale, etc.)", "the set of characterization factors/models is published and accessible" and that third parties were granted to "freely generate additional, consistent factors and to further develop models, e.g. incorporating further geographical/emission situation, temporal and speciation differentiation". These principles are maintained and transposed in Sect. 2.5 of the GLAM Vol.I (Frischknecht et al. 2016) where method developers "are recommended to document comprehensively and transparently the impact assessment models and resulting LCIA methods", to document "the data sources, underlying assumptions and modeling choices" and "explicitly report reference states and their rationale, based on a set of criteria".

\subsection{Possible improvements of the LANCA $^{\circledast}$ model}

The authors of the model proposed a method for a GIS-based application of the LANCA taking into account the spatial variability of soil properties and providing a spatially differentiated map at global scale for groundwater distance (Bos et al. 2020). Ulrike Bos and her collaborators (2020) show the advantages of site-specific CFs. Noteworthy, this paper represents a refinement of the model because the calculation structure was made clearer, the typical range of some key parameters was reported, and the documentation extended with respect to LANCA ${ }^{\circledR} 2.0$. As an example, the humus content has been associated with the organic matter content, a much more available data; the reference for the surface runoff calculation has been introduced in the calculation process. As highlighted by Thoumazeau and coworkers (2019) and on the basis of the results of this work (see also Supplementary Material - Annex 4), some input parameters and the related empirical equations are based on very site-specific data and may not be robust enough to compute a global assessment of the soil quality. All these observations together with the results obtained in this work are reflected in Table 7 the following table. In the wait for improvements by Bos et al. (2020) to be transposed into a revision of the current version LANCA ${ }^{\circledR} 2.0$ and besides that, some issues seem to be still open. For example, it is recommended a homogenization of the calculation processes in terms of validity, terminologies and units of measurement to align them to the ones used for country-default CFs. The guidance related to some factors, e.g. the sealing factor, is not well documented and easy to access. Conversely, the advantage of a standardized land use classification system like CORINE (Coordination of Information on the Environment, Büttner et al. 2017) is well proved and is however a thorny issue. Itf it is indeed undeniable that LANCA follows a land use classification, fully ILCD compliant and that few options can ensure global coverage and a satisfactory granularity (Koellner et al. 2013a, b). The problem of a uniform classification of the geographical information is external to the method. However, it might be possible to improve guidance and to determine archetypical situations across land use types and regions and improve inventory entries and methods accordingly.

All above considerations and paper findings have been condensed in Table 7.

\section{Conclusions}

LANCA $®$ is the reference model to be applied "with caution" for land use impact calculation for the Environmental Footprint - pilot and transition phase - for soil impact assessment. The rationale behind the choice is that the model can rely on (i) multi-indicator approach and to its ability to grasp soil impacts associated to each land use intervention, 
(ii) coverage of land use inventory flows following the International Reference Life Cycle Data System and (iii) global spatial coverage with world and country default characterisation factors (Sala et al. 2019). In this work, the default CFs have been used to evaluate LANCA adoption in spatially differentiated conditions considering a specific land use in a study site. Four out of five indicators converged to show a decrease of the soil quality in the region with respect to the reference situation. However, the CFs related to soil resistance, physiochemical filtration and groundwater regeneration showed, respectively a difference of 3,2,1 order of magnitude while erosion potential and physiochemical had opposite sign with respect to the default CFs. Divergences can be explained as lack of an explicit, complete-in-scope guidance especially when the required specific data were not available (despite the test occurred in a well-covered and data-abundant region such as in the study site). More generally, the lack of access to the underpinning methods and datasets used to calculate country default characterisation factors and to the calibration process related to submodels hinder full replicable results. Above that, crucial in site-specific assessments is the choice of the reference situation. Indeed, the choice of the latter implied the choice of a distant area where the geomorphology, climatic and pedogenic values were not comparable to the foreground condition. These data - namely annual precipitation, slope and granulometry - have the most relevant effects on $\mathrm{CF}$ values and can explain most of the divergences. This can be a general problem in Europe, middle East and other regions where the reference condition has disappeared centuries ago as the result of historical and profound human interventions and modifications. Inevitably, an unguided choice of the reference condition leads to a high user arbitrariness and to consequent scarce replicability of the results. This is relevant for site-specific applications as well to ensure consistency, replicability and quality assurance of the model. In this light, this work suggests working for an upgrade of the model to favour its early and undisputed adoption especially in sight of spatially differentiated LCIA models.

Supplementary Information The online version contains supplementary material available at https://doi.org/10.1007/s11367-021-01981-3.

Funding Open access funding provided by Alma Mater Studiorum Università di Bologna within the CRUI-CARE Agreement.

Open Access This article is licensed under a Creative Commons Attribution 4.0 International License, which permits use, sharing, adaptation, distribution and reproduction in any medium or format, as long as you give appropriate credit to the original author(s) and the source, provide a link to the Creative Commons licence, and indicate if changes were made. The images or other third party material in this article are included in the article's Creative Commons licence, unless indicated otherwise in a credit line to the material. If material is not included in the article's Creative Commons licence and your intended use is not permitted by statutory regulation or exceeds the permitted use, you will need to obtain permission directly from the copyright holder. To view a copy of this licence, visit http://creativecommons.org/licenses/by/4.0/.

\section{References}

Baitz M, Makishi-colodel C, Kupfer T et al (2011) GaBi Database and Modelling Principles

Barbera G, Cullotta S (2014) The Halaesa landscape (III B C) as ancient example of the complex and bio-diverse traditional Mediterranean polycultural landscape. Landsc Hist 35:53-66. https:// doi.org/10.1080/01433768.2014.981395

Batey T (2009) Soil compaction and soil management - a review. Soil Use Manag 25:335-345. https://doi.org/10.1111/j.1475-2743. 2009.00236.x

Beck T, Bos U, Wittstock B et al (2010) Land use indicator value calculation in life cycle assessment - Method Report. Fraunhofer Institute for Building Physics, Stuttgart

Bidoglio G, Berger M, Finkbeiner M (2019) An environmental assessment of small hydropower in India: the real costs of dams' construction under a life cycle perspective. Int J Life Cycle Assess 24:419-440

Bos U, Horn R, Beck T et al (2016) LANCA ® Characterization factors for life cycle impact assessment - version 2.0. Fraunhofer Verlag, Stuttgart

Bos U, Maier SD, Horn R et al (2020) A GIS based method to calculate regionalized land use characterization factors for life cycle impact assessment using LANCA®. Int J Life Cycle Assess 25:12591277. https://doi.org/10.1007/s11367-020-01730-y

Büttner G, Kosztra B, Soukup T et al (2017) European Environment Agency. CLC2018 Technical Guidelines. (2017) Online, (3436), 0-60. Retrieved from https://land.copernicus.eu/user-corner/ technical-library/clc2018technicalguidelines_final.pdf

Chow VT, Maidment R, Mays LW (1988) “Appl Hydrol”. McGraw Hill Book Company, Singapore

De Laurentiis V, Secchi M, Bos U et al (2019) Soil quality index: exploring options for a comprehensive assessment of land use impacts in LCA. J Clean Prod 215:63-74. https://doi.org/10. 1016/j.jclepro.2018.12.238

EC-European Commission (2017) PEFCR guidance document, guidance for the development of product environmental footprint category rules (PEFCRs), version 6.3, December 2017

EC-European Commission (2013) Commission Recommendation on the use of common methods to measure and communicate the life cycle environmental performance of the products and organizations. Annex II: Product Environmental Footprint (PEF) Guide to Commission Recommendation on the use of common methods to measure and communicate the life cycle environmental performance of the products and organizations. Official Journal of the European Union. 2013;56.

EC-European Commission (2010) Commission Decision of 10 June 2010 on guidelines for the calculation of land carbon stocks for the purpose of Annex V to Directive 2009/28/EC. Off J Eur Union L 151:19

EC-JRC (2010) International reference life cycle data system (ILCD) handbook: framework and requirements for life cycle impact assessment models and indicators

Emilia-Romagna R (2018) Servizio Geologico e Sismico dei Suoli, «Catalogo dei dati geografici,» [Online]. Available: https://geo. regione.emilia-romagna.it/geocatalogo/. [Accessed September 2018].

FAO (2012) Global ecological zones for FAO forest reporting : 2010 update. For Resour Assess Work Pap 179 
Frischknecht R, Jolliet O, Mila i Canals L, Berger M, Fantke P, Grant $\mathrm{T}$ (2016) Global guidance for life cycle impact assessment indicators. Paris

Frischknecht R, Jolliet O (2019) Global guidance on environmental life cycle impact assessment indicators. Paris

Jeswani HK, Hellweg S, Azapagic A (2018) Accounting for land use, biodiversity and ecosystem services in life cycle assessment: impacts of breakfast cereals. Sci Total Environ 645:51-59

JRC European Commission (2011) Recommendations for life cycle impact assessment in the European context EUR 24571. Luxembourg Publications Office of the European Union, Luxembourg

Garrigues E, Corson MS, Angers DA et al (2012) Soil quality in life cycle assessment: towards development of an indicator. Ecol Indic 18:434-442. https://doi.org/10.1016/j.ecolind.2011.12.014

Horn R, Maier S (2018) LANCA® - Characterization Factors for Life Cycle Impact Assessment, Version 2.5, University of Stuttgart, IABP-GaBi, Fraunhofer Institute for Building Physics IBP, dept. $\mathrm{GaBi}$.

Hellweg S, Mila i Canals L, (2014) Emerging approaches, challenges and opportunities in life cycle assessment. Science 344:11091113. https://doi.org/10.1126/science.1248361

Koellner T, de Baan L, Beck T et al (2013a) Principles for life cycle inventories of land use on a global scale. Int J Life Cycle Assess 18:1203-1215. https://doi.org/10.1007/s11367-012-0392-0

Koellner T, de Baan L, Beck T et al (2013b) UNEP-SETAC guideline on global land use impact assessment on biodiversity and ecosystem services in LCA. Int J Life Cycle Assess 18:1188-1202. https://doi.org/10.1007/s11367-013-0579-z

Milà Canals L, Bauer C, Depestele J et al (2007) Key elements in a framework for land use impact assessment within LCA. Int J Life Cycle Assess 12:5-15. https://doi.org/10.1065/lca2006.05.250

Morgan RPC (2005) Soil erosion \& conservation, 3rd edn. Blackwell Publishing, Hoboken

Oberholzer HR, Knuchel RF, Weisskopf P, Gaillard G (2012) A novel method for soil quality in life cycle assessment using several soil indicators. Agron Sustain Dev 32:639-649. https://doi.org/10. 1007/s13593-011-0072-7

Orgiazzi A, Ballabio C, Panagos P, Jones A, Fernandex-Ugalde O (2018). LUCAS Soil, the larghest expandable soil dataset for Europe: a review. European Journal of Soil Science 69:140-153

Panagos P, Meusburger K, Ballabio C et al (2014) Soil erodibility in Europe: a high-resolution dataset based on LUCAS. Sci Total Environ 479:189-200. https://doi.org/10.1016/j.scitotenv.2014. 02.010

Panagos P, Borrelli P, Poesen J et al (2015a) The new assessment of soil loss by water erosion in Europe. Environ Sci Policy 54:438447. https://doi.org/10.1016/j.envsci.2015.08.012

Panagos P, Borrelli P, Meusburger K et al (2015b) Estimating the soil erosion cover-management factor at the European scale. Land Use Policy 48:38-50. https://doi.org/10.1016/j.landusepol.2015. 05.021

Pfister S, Oberschelp C, Sonderegger T (2020) Regionalized LCA in practice: the need for a universal shapefile to match LCI and LCIA. Int J Life Cycle Assess 25:1867-1871
Saad R, Koellner T, Margni M (2013) Land use impacts on freshwater regulation, erosion regulation, and water purification: a spatial approach for a global scale level. Int J Life Cycle Assess 18:12531264. https://doi.org/10.1007/s11367-013-0577-1

Saad R, Margni M, Koellner T et al (2011) Assessment of land use impacts on soil ecological functions: Development of spatially differentiated characterization factors within a Canadian context. Int J Life Cycle Assess 16:198-211. https://doi.org/10.1007/ s11367-011-0258-x

Sala S, Benini L, Castellani V et al (2019) Suggestions for the update of the Environmental Footprint Life Cycle Impact Assessment: Impacts due to resource use water use land use and particulate matter. European Commission, Luxembourg

Saltelli A (2002) Sensitivity analysis for importance assessment-risk analysis. Risk Anal 22(3):579-590

Sonderegger T, Pfister S, Hellweg S (2020) Assessing impacts on the natural resource soil in life cycle assessment: methods for compaction and water erosion. Environ Sci Technol 54:6496-6507

Thoumazeau A, Bustany C, Rodrigues J, Bessou C (2019) Using the LANCA ${ }^{\circledR}$ model to account for soil quality within LCA: first application and approach comparison in two contrasted tropical case studies. Indones J Life Cycle Assess Sustain 33:1-13. https:// doi.org/10.52394/ijolcas.v3i1.42

Toth G, Jones A, Montanarella L (eds.) (2013) LUCAS Topsoil Survey. Methodology, data and results. JRC Technical Reports. Luxembourg. Publications Office of the European Union, EUR 26102 - Scientific and Technical Research series - ISSN 1831-9424 (online); ISBN 978-92-79-32542-7. https://doi.org/10.2788/97922

UNEP/SETAC Life Cycle Initiative (2021) Global LCIA guidance phase 3 - creation of a global life cycle impact assessment method: scoping document. Paris

Vázquez-Rowe I, Marvuglia A, Flammang K et al (2014) The use of temporal dynamics for the automatic calculation of land use impacts in LCA using R programming environment: a case study for increased bioenergy production in Luxembourg. Int J Life Cycle Assess 19:500-516. https://doi.org/10.1007/ s11367-013-0669-y

Vidal-Legaz B, Sala S, Antòn A et al (2016) Land-use related environmental indicators for life cycle assessment - analysis of key aspects in land use modelling

Vidal Legaz B, Maia De Souza D, Teixeira RFM et al (2017) Soil quality, properties, and functions in life cycle assessment: an evaluation of models. J Clean Prod 140:502-515. https://doi.org/10. 1016/j.jclepro.2016.05.077

Zampori L, Pant R (2019) Suggestions for updating the product environmental footprint (PEF) method. JRC Tech Reports 248. https:// doi.org/10.2760/424613

Publisher's Note Springer Nature remains neutral with regard to jurisdictional claims in published maps and institutional affiliations. 